\title{
The Interactional Architecture of the Language Classroom
}

\author{
Dr. Paul Seedhouse, Newcastle University
}

\section{Introduction}

In this article I provide a summary of some of the key ideas of Seedhouse (2004), which attempts to answer the question 'How is L2 classroom interaction organised?' I describe the overall organisation of L2 classroom interaction, introducing the concept of the rational design of institutional interaction and then identify the institutional goal as well as three interactional properties which derive directly from the goal. I then identify the basic sequence organisation of L2 classroom interaction as well as an emic methodology for its analysis. An example of data analysis is then provided, including discussion of socially distributed cognition and learning.

\section{The Core Institutional Goal}

CA attempts to understand the organisation of institutional interaction as being rationally derived from the core institutional goal, rather than being accidental or unmotivated. Therefore, the first step towards describing the interactional architecture of L2 classroom interaction is to identify the institutional core goal, which is that the teacher will teach the learners the L2. This core institutional goal remains the same wherever the L2 lesson takes place and whatever pedagogical framework the teacher is working in. This is a most important point. In many kinds of institutions, e.g. businesses, the institutional goal may vary considerably even between businesses in the same town. However, in L2 teaching the institutional goal of the teacher teaching the L2 to the learners remains constant whatever the teaching methods, whatever the L1 and L2 and wherever in the world the L2 is taught. It remains the same if the teacher delegates some responsibility to learners in a learner-centred or learner autonomy approach. From this core goal a number of consequences issue both logically and inevitably which affect the way in which L2 classroom interaction is accomplished. Drew and Heritage (1992: 26) suggest that each institutional form of interaction may have its own unique fingerprint, “comprised of a set of interactional 
practices differentiating (it) both from other institutional forms and from the baseline of mundane conversational interaction itself.”

\section{Three Interactional Properties}

There are three interactional properties which derive directly from the core goal, and these properties in turn necessarily shape the interaction. The three properties follow in consecutive sequence from each other and constitute part of the unique fingerprint of L2 classroom interaction and part of its context-free machinery.

1. Language is both the vehicle and object of instruction.

2. There is a reflexive relationship between pedagogy and interaction and interactants constantly display their analyses of the evolving relationship between pedagogy and interaction.

3. The linguistic forms and patterns of interaction which the learners produce in the L2 are potentially subject to evaluation by the teacher in some way.

\section{Property One}

Language is "Both the vehicle and object of instruction." (Long 1983: 9). This property springs inevitably from the core goal. The core goal dictates that the L2 is the object, goal and focus of instruction. It must be taught, and it can only be taught through the medium or vehicle of language. Therefore language has a unique dual role in the L2 classroom in that it is both the vehicle and object, both the process and product of the instruction; see Seedhouse (2004) for exemplification of this point. In other forms of classroom education (history, engineering) language is only the vehicle of the teaching. This property creates an extra layer of complexity in the interaction which needs to be portrayed in our analyses.

\section{Property Two}

There is therefore a reflexive relationship between pedagogy and interaction. This means that as the pedagogical focus varies, so the organisation of the interaction varies. This point is illustrated through analyses in the monograph. However, this relationship also means that the L2 classroom has its own interactional organisation which transforms the pedagogical focus (task-as-workplan) into interaction (task-inprocess). The omnipresent and unique feature of the L2 classroom is this reflexive relationship between pedagogy and interaction. So whoever is taking part in L2 classroom interaction and whatever the particular activity during which the 
interactants are speaking the L2, they are always displaying to one another their analyses of the current state of the evolving relationship between pedagogy and interaction and acting on the basis of these analyses. We can see how this works even in the first exchange a Chinese L1 beginner makes in his first English class in the extract below. $\mathrm{T}=$ teacher. $\mathrm{L} 1=$ identified learner. $\mathrm{LL}=$ unidentified learners.

\section{Extract 1}

1 T: OK my name's,

2 LL: my name's,

3 T: OK, (.) er, hello, (addresses L1) my name’s John Fry.

4 L1: (.) my name's John Fry,

5 T: oh!

6 LL: (laugh)

$7 \quad$ L1: my name's Ping. Ping.

8 T: Ping? yes hello, ${ }^{\circ}$ you say ${ }^{\circ}$ (whispers) hello.

9 L1: hello my name is my name’s Ping.

(British Council 1985 volume 1: 15)

We can see in line 4 that L1 displays an analysis of the current relationship between pedagogy and interaction as being that he must repeat whatever the teacher says. It is easy to see how this occurs, since in lines 1 and 2 the required relationship between pedagogy and interaction was just that. T, however, displays in lines 5 and 8 that his analysis is that this is not the required relationship and that L1 should instead produce a specific string of forms including L1's own name. L1 then changes his analysis of the relationship between pedagogy and interaction so that in line 9 it finally conforms to that required by $\mathrm{T}$.

Property Three

The linguistic forms and patterns of interaction which the learners produce in the L2 are potentially subject to evaluation by the teacher in some way. As van Lier (1988: 32) puts it, "Everyone involved in language teaching and learning will readily agree that evaluation and feedback are central to the process and progress of language learning." This property does not imply that all learner utterances in the L2 are followed by a direct and overt verbalised evaluation by the teacher, as the data show this clearly not to be the case. It means that all learner utterances are potentially subject to evaluation by the teacher. This third property derives logically from the second property; since the linguistic forms and patterns of interaction which the learners produce in the L2 are normatively linked in some way to the pedagogical 
focus which is introduced, it follows that the teacher will need to be able to evaluate the learners' utterances in the L2 in order to match the reality to the expectation. This study proposes that these three properties are universal, i.e., they apply to all L2 classroom interaction and they are inescapable in that they are a consequence of the core institutional goal and the nature of the activity. Furthermore, the data from many different countries, types of institutions and types of lesson which are analysed in Seedhouse (2004) demonstrate the universality of these properties. These properties, then, form the foundation of the architecture and of the unique institutional 'fingerprint' of the L2 classroom.

\section{A Basic Sequence Organisation}

Although L2 classroom interaction is extremely diverse and fluid, it is nonetheless possible to state a basic sequence organisation which applies to all L2 classroom interaction, as follows.

1. A pedagogical focus is introduced. Overwhelmingly in the data this is introduced by the teacher but it may be nominated by learners.

2. At least two persons speak in the $\mathrm{L} 2$ in normative orientation to the pedagogical focus.

3. In all instances, the interaction involves participants analysing this pedagogical focus and performing turns in the L2 which display their analysis of and normative orientation to this focus in relation to the interaction. Other participants analyse these turns in relation to the pedagogical focus and produce further turns in the L2 which display this analysis. Therefore, participants constantly display to each other their analyses of the evolving relationship between pedagogy and interaction.

Through this sequence the institution of the L2 classroom is talked into being. This is the case because introducing the pedagogical focus is directly implicative of the institutional goal, i.e. to teach the learners the L2.

\section{An Analytical Methodology}

The idea that an analytical procedure or methodology can emerge from the structure of interaction is a familiar one in CA. Our task as analysts is to explicate how L2 classroom interactants analyse each others' turns and make responsive moves in 
relation to the pedagogical focus. The description of the interactional architecture of the L2 classroom above, specifically the properties and basic sequence organisation, provides the analyst with a ready-made emic analytical procedure. The participants display in their turns their analyses of the evolving relationship between pedagogy and interaction, i.e. how the pedagogical focus relates to the turns produced in L2. Therefore, the methodology can be stated in this way: The analyst follows exactly the same procedure as the participants and traces the evolving relationship between pedagogy and interaction, using as evidence the analyses of this relationship which the participants display to each other in their own turns.

So the methodology which is used for the analysis of L2 classroom interaction is the next-turn proof procedure in relation to the pedagogical focus. In the vast majority of cases in the database we can state the procedure more specifically as follows. The classroom teacher compares the linguistic forms and patterns of interaction which the learner produces with the pedagogical focus which s/he originally introduced and performs an analysis and evaluation on that basis. The analyst can do exactly the same thing, comparing the teacher's intended pedagogical focus with the linguistic forms and patterns of interaction which the learner produces, and then analysing the interaction on the basis of the match or mismatch. This methodology is exemplified in numerous analyses in Seedhouse (2004) and in the next section.

\section{Analysis of Data}

In this section I analyse a sample of data to illustrate the above points and to provide an example of how analysis may be conducted.

\section{Extract 2}

1 T: Vin, have you ever been to the movies? What's your favorite movie?

2 L: Big.

3 T: Big, OK, that's a good movie, that was about a little boy inside a big man, wasn't it?

$4 \quad$ L: $\quad$ Yeah, boy get surprise all the time.

5 T: Yes, he was surprised, wasn't he? Usually little boys don't do the things that men do, do they?

$6 \quad$ L: No, little boy no drink.

7 T: That's right, little boys don't drink.

(Johnson 1995: 23) 
If we analyse turn-taking, sequence organisation, repair and topic at the same time, we can see that the learner in extract 2 is able to develop a sub-topic and is allowed interactional space. In line $1 \mathrm{~T}$ introduces the carrier topic (films) and constrains L's turn in line 2, which is a minimum response appropriate to the turn. In line $3 \mathrm{~T}$ shifts the topic slightly from the carrier topic (films) to the sub-topic of the specific film "Big" which has been nominated by L. In doing so T validates and approves L's sub-topic by calling it a good movie. This particular comedy movie involves a "magical" transfer in which a young boy's mind is transferred into a man’s body. T constrains L's next turn by making a general statement summarising the plot of the movie ("that was about a little boy inside a big man”) together with a tag question. This allocates $\mathrm{L}$ a turn, constrains the topic of L's turn (the plot of the film “Big”) and simultaneously provides the other students in the class (who may not know the film) with sufficient information to be able to follow the evolving dialogue. The tag question effectively requires $\mathrm{L}$ to confirm the accuracy of T's summary of the film's plot, but also allows $\mathrm{L}$ the interactional space (if $\mathrm{L}$ wishes) to develop the sub-topic. $\mathrm{L}$ does confirm T's summary of the sub-topic and then chooses to contribute new information which develops the sub-topic (the film's plot), namely in line 4 ("boy get surprise all the time”). This utterance is linguistically incorrect, although the propositional content is clear to T. Since L is introducing 'new' information, L is effectively developing the sub-topic, to which $\mathrm{T}$ could respond in his/her next turn. In line 5 , there is positive evaluation of the propositional content of the learner utterance followed by an expansion of the learner utterance into a correct sequence of linguistic forms. The type of repair used is embedded correction (Jefferson 1987: 95), that is, a correction done as a by-the-way occurence in the context of a social action, which in this case is an action of agreement and confirmation.

This form of correction and expansion is highly reminiscent of adult-child conversation, and the technique being used by the teacher here is often termed scaffolding (Johnson 1995: 75). Further in line 5, T then accepts L's invitation to develop the sub-topic, and T's statement “usually little boys don't do the things that men do" also simultaneously provides the other students in the class with an explanation as to why the boy was surprised all the time, thus enabling them to continue to follow the evolving dialogue. The tag question (line 5) again allocates $\mathrm{L}$ a turn and effectively allots him the interactional space to continue to develop the sub-topic should he wish to do so. L uses 'no' in line 6 to agree with the negative 
tag-question and chooses to develop the sub-topic by providing an example from the film to illustrate T’s previous generalised statement with: "little boy no drink”. Again his utterance is linguistically incorrect, although the propositional content is clear. Since $\mathrm{L}$ is again introducing 'new' information, $\mathrm{L}$ effectively invites $\mathrm{T}$ to respond to this elaboration of the sub-topic in T's next turn. T's response in line 7 is similar to line 5 in that $\mathrm{T}$ performs an action of agreement, simultaneously corrects L's utterance (using embedded correction) and displays a correct version for the other students.

I would now like to demonstrate that the teacher is balancing multiple and sometimes conflicting demands "The complexity of the classroom is such that several things may be going on publicly through talk at the same time." The teacher is orienting to five separate (though related) concerns simultaneously.

1) The teacher's pedagogical focus (Johnson 1995: 23) "was to allow the students to share their ideas and possibly generate some new vocabulary words within the context of the discussion.” This implies that the teacher needs to control the overall topic whilst allowing the learners some interactional space to develop their own sub-topics. The teacher has to orient, then, to an overall pedagogical plan.

2) The teacher also has to respond to the ideas and personal meanings which the learner chooses to share, and does so successfully in that he/she develops the sub-topic introduced by the learner. So in lines 5 and 7 the teacher responds to the learner utterance with a conversational action of agreement which validates the propositional content of the utterance as well as the introduction of the sub-topic.

3) The teacher also responds to linguistic incorrectness in the individual learner's utterances and conducts embedded repair on them. The linguistic repair is performed in a mitigated way because it is prefaced by an action of agreement and approval and because this type of embedded correction can be treated as a by-the-way matter.

4) The teacher must also orient to the other learners in the class. One problem faced by teachers is that individual learners often produce responses which are inaudible or incomprehensible to the other students in the class. So in lines 5 and 7 the teacher is simultaneously displaying approved versions of learner utterances so that the other learners are able to follow the propositional content of the interaction and are also able to receive correctly formed linguistic input.

5) One of the most difficult feats in L2 teaching is to maintain a simultaneous dual focus on both form and meaning (Seedhouse 1997). The teacher in the above extract is skilfully managing to maintain elements of a simultaneous dual focus on both form 
and meaning. There is a focus on form in that the teacher upgrades and expands the learner's utterances on a linguistic level, which means that the learners have a linguistically correct utterance which can function as both model and input. The focus is simultaneously also on meaning in that the learner is able to contribute 'new' information concerning his/her personal experiences and to develop a sub-topic.

\section{Socially Distributed Cognition}

In this section I develop a CA perspective on socially-distributed cognition in relation to L2 classroom interaction. The organisations of sequence, turn-taking and repair are employed by interactants in order to display not only their social actions but also their understandings of the other's social actions to each other; these organisations constitute part of the architecture of intersubjectivity, or how people understand each other. I will illustrate this by focusing on lines 4 and 5 only of extract 2. In line $4 \mathrm{~L}$ displays an understanding of T's turn in line 3. How do we know what the understanding is which $\mathrm{L}$ has displayed in line 4? We know this by normative reference to the interactional organisations. There are two kinds of interactional evidence. Firstly, the kind of action which L's turn performs; L confirms T's summary of the sub-topic and contributes new information which develops the sub-topic (the film's plot), and exemplifies what happened in the film's plot ("boy get surprise all the time”). The second piece of evidence is that T's turn in line 5 confirms that L's turn displays a correct understanding of T's turn in line 3. So we know this by reference to the turn-taking system, $\mathrm{L}$ having been specifically allocated a turn by the tag question in line 3 and by reference to sequence organisation, which tells us that line 4 is an answer to a question about the plot of the film. In interactional sequences, then, evidence in relation to socially distributed cognition is available and piles up, layer upon layer. The utterance in line 4 is linguistically incorrect, although we can see that the propositional content is clear to T, since T's turn in line 5 displays understanding of the content of L's turn in line 4 . T displays understanding by positively evaluating the propositional content of the learner utterance followed by an expansion of the learner utterance into a correct sequence of linguistic forms, using embedded correction in the context of an action of agreement and confirmation.

It should be made quite explicit at this point that CA does not claim to be able to establish the cognitive state of individuals in isolation. What it is able to portray and explicate, however, is the progress of intersubjectivity or socially distributed 
cognition. CA aims to "identify ways in which participants themselves orient to, display, and make sense of one another's cognitive states (among other things)" (Drew 1995: 79). The point is, then, that the interactants in extract 2 are displaying to each other (and to the rest of the class and to the analyst) their understanding of each others' utterances by means of and by reference to the organisation of turn-taking, sequence and repair. This demonstrates what Schegloff (1991: 152) means by "the embeddedness, the inextricable intertwinedness, of cognition and interaction". The CA analysis not only demonstrates what understandings the interactants display to each other, but also how they do so by normative reference to the interactional organisations. In other words, we gain access to their displays of understanding to each other in the same way that they gain this access, i.e. by reference to the interactional organisations; this is what is meant by developing an emic perspective. Psychology, SLA and CA do not have any means of establishing a direct window into an individual's cognitive state whilst they are engaged in L2 classroom interaction.

We do need to try to conceptualise what this might mean in practice, though; what factors are involved in an individual's cognitive state in such a stream of interaction? Looking at line 4 of extract 2, $\mathrm{L}$ is not merely producing an utterance in the L2; any utterance is a document on many levels and we saw above that L2 classroom interaction in particular operates on a number of levels simultaneously. The utterance is a display of the learner's analysis of the prior utterance of an interactant, it performs a social action in response and it positions the learner in a social system. It displays an understanding of the current context (sequential, social and L2 classroom context) and also renews it. It documents the learner's cognitive, emotional and attitudinal states: Note that this does not mean it gives a direct window into these states. In the specific case of the L2 classroom the learner's utterance may in addition be delivered in the L2 and may thereby document his/her actual developmental level as well.

So we can see that a part of what is meant by the cognitive state of a learner involved in L2 classroom interaction is inextricably entwined and engaged with the unique sequential, social and contextual environment in which he/she is engaged. It is argued that this part of the individual's cognitive state can be portrayed emically in situ , that is, in that unique sequential environment. This is not to suggest that this provides anything like the whole picture, nor that the methods employed by SLA and psychology are not useful in portraying other aspects of the full picture in relation to 
cognition. The point to be made, however, is that CA is able to make a major contribution to the SLA project in terms of the portrayal of socially distributed cognition. Moving the focus back to the general relationship between cognition and interaction, Schegloff (1991: 154) suggests that "the structures of interaction penetrate into the very warp" of cognition, so that, for example, an "understanding-display" device (i.e., the next-turn-proof-procedure) is built into the organisation of turn-taking and sequence. In the same way, if we wish to fully understand the processes of cognition in relation to instructed L2 acquisition, it is vital to understand how L2 classroom interaction is organised.

\section{Learning}

We will now attempt a CA analysis of learning in relation to extract 2 in three stages. Firstly, what can we say about the learner's actual developmental level or current ability in L2? We can note in lines 4 and 6 that his grammatical resources are fairly limited. Nonetheless, the learner is able to make use of these limited resources to nominate a sub-topic (line 2) and develop the sub-topic by exemplifying T's comments (lines 4 and 6). Although it can be challenging for children to interact with the teacher in a classroom setting, even in the L1, we can see that $\mathrm{L}$ is able to use the turn-taking and sequence organisations of the L2 proficiently, producing a correct response to a negative tag-question (line 4) and a positive tag question (line 6). As we saw above, T's turn in line 5 operates on a number of levels. From the learner's perspective, it is not just a matter of understanding the propositional content of what $\mathrm{T}$ says in the L2; it is also a matter of analysing what social and sequential action $\mathrm{T}$ is performing and what an appropriate social and sequential action in response would be. So we can see that $\mathrm{L}$ skilfully manages to co-construct meaning with $\mathrm{T}$ in the $\mathrm{L} 2$ from his limited grammatical resources.

Secondly, what can we say about the learning environment in terms of input to the language learning process and facilitation of upgrading as a result of the interaction? Line 5 reads: "Yes, he was surprised, wasn't he?” We will break its contribution down into four points. Firstly, the utterance places the sequence within the teacher's overall pedagogical plan for the lesson, which "was to allow the students to share their ideas and possibly generate some new vocabulary words within the context of the discussion" (Johnson 1995: 23). Secondly, it may promote positive affect and motivation in that the teacher engages with the ideas and personal 
meanings which the learner chooses to share and produces a conversational action of agreement which validates the utterance. It then demonstrates confidence in the learner by returning the floor to him with the tag question. Thirdly, it makes it possible for the other learners in the class to follow the topic of the interaction and to receive correctly formed linguistic input. There is no evidence in the transcripts as to whether the other learners have done so or not. However, Ohta (2001) shows (by recording and transcribing the private talk of individually microphoned students in a classroom) that students are capable of using recasts in which they are not personally involved as negative evidence and of displaying uptake in their private talk. Fourthly, and most importantly, there is positive evaluation of the propositional content of the learner utterance followed by an expansion of the learner utterance into a correct sequence of linguistic forms or embedded correction. In terms of input, the teacher provides a corrected version of the learner's turns in lines 4 and 6 whilst retaining a focus on meaning. This form of correction and expansion is highly reminiscent of adult-child conversation. The technique being used by the teacher here is often termed scaffolding (Johnson 1995: 75). Ohta defines Vygotsky's Zone of Proximal Development (ZPD) in relation to SLA in the following terms: "For the L2 learner, the ZPD is the distance between the actual developmental level as determined by individual linguistic production, and the level of potential development as determined through language produced collaboratively with a teacher or peer" (Ohta 2001: 9).

What we can see in this extract, then, is how a ZPD is talked into being through the organisation of the interaction. Specifically, we see a neat juxtaposition of the learner's actual developmental level in lines 4 and 6 with the potential level in lines 5 and 7. The distinctive CA contribution is to show how learning is constructed by the use of interactional resources and to explicate the progress of their learning and their socially distributed cognition or intersubjectivity. From a broader perspective, CA is able to explicate the reflexive relationship between pedagogy and interaction and hence how learning takes place through the interaction; the monograph as a whole demonstrates this point.

Thirdly, how does the process of instructed L2 learning progress? Seedhouse (2004) suggests that the canonical way in which an L2 lesson progresses is that the L2 teacher introduces a pedagogical focus and the learners produce specific linguistic forms and patterns of interaction in the L2 in normative orientation to the pedagogical 
focus. The teacher then evaluates the learners' turns and progresses the lesson in a particular direction on the basis of that evaluation. So in the above extract we can see that the teacher analyses the learner's contribution positively and continues to promote the learner's nominated topic. The point is, then, that we as analysts have access to the same interactional evidence of the learners' learning states as the teachers have ${ }^{\mathrm{i}}$ as well as access to the steps the teacher takes in reaction to such evidence. In other words, we have access to the same emic perspective of the learning process in interaction to which the teacher has access. This type of evidence of learning may complement the evidence of learning gathered through mainstream SLA studies. Schegloff (1991) demonstrates that CA gives access to socially-distributed cognition. In the same way, CA gives access to socially-distributed language learning processes. As with cognition, this is only one part of the whole picture, but a useful one nevertheless.

\section{Conclusions}

In the 1960s the dominant view in linguistics was the Chomskian one that conversation was too disordered and degenerate to be studied; that viewpoint is no longer expressed nowadays. However, for many years researchers in the area of language learning have shied away from classroom interaction, regarding it as an excessively complex, heterogenous and a particularly messy source of data. However, this study suggests that, as with conversation, there is also order at all points in L2 classroom interaction.

A persistent criticism of SLA research by classroom language teachers has been that it has been top-down, driven by theory and concepts which may have little relevance to classroom practice. Furthermore, little attention or interest has been shown in what language teachers actually do and classroom practice has not generated theory; in other words, there has been one-way traffic between theory and practice. I hope that the model and methodology presented in Seedhouse (2004) will enable pedagogical theory to be generated inductively from interactional data and enable two-way traffic between theory and practice. 


\title{
References
}

British Council (1985). Teaching and Learning in Focus. Edited Lessons (Four Volumes). London: British Council.

Drew, P. (1995). Conversation Analysis. In J. Smith, R. Harré, L. van Langenhove \& P. Stearns (Eds.), Rethinking Methods in Psychology, pp. 64-79,. London: Sage.

Drew, P. and Heritage, J. (eds). (1992). Talk at Work: Interaction in Institutional Settings. Cambridge: Cambridge University Press.

Jefferson, G. (1987). On Exposed and Embedded Correction in Conversation. In G. Button and J. Lee (eds.), Talk and Social Organisation, pp. 86-100, Clevedon: Multilingual Matters.

Johnson, K. (1995). Understanding Communication in Second Language Classrooms. Cambridge: Cambridge University Press.

Long, M. (1983). Inside the 'Black Box’. In H. Seliger \& M. Long (Eds.), Classroom Oriented Research in Second Language Acquisition, pp. 3-36, Rowley: Newbury House.

Ohta, A.S. (2001). Second Language Acquisition Processes in the Classroom. Mahwah, NJ: Lawrence Erlbaum.

Schegloff, E.A. (1991). Conversation Analysis and Socially Shared Cognition. In L. Resnick, J. Levine \& S. Teasley (Eds.), Perspectives on Socially Shared Cognition, pp. 150-171, Washington DC: American Psychological Association.

Seedhouse, P. (1997). Combining Form and Meaning. English Language Teaching Journal, 51(4), 336-344.

Seedhouse, P. (2004). The Interactional Architecture of the Language Classroom: A Conversation Analysis Perspective. Malden, MA: Blackwell.

Van Lier, L. (1988). The Classroom and the Language Learner. New York: Longman.

\begin{abstract}
Author's References:
Dr. Paul Seedhouse is Professor of Educational and Applied Linguistics and Postgraduate Research Director, School of Education, Communication and Language Sciences, Newcastle University. He has published many articles on language teaching and conversation analysis and is the author of several books on these topics, including The Interactional Architecture of the Language Classroom: A Conversation Analysis Perspective (2004, Blackwell), which was short-listed for the prestigious British Association of Applied Linguistics Book Prize, 2005.
\end{abstract}

i Although we do not have access to all of the cues which the teacher does, e.g. non-verbal ones. 